\title{
Climatic perspectives on Sahelian desiccation: 1973-1998
}

\author{
Mike Hulme* \\ Climatic Research Unit, School of Environmental Sciences, University of East Anglia, Norwich NR4 7TJ, UK
}

Received 2 August 2000

\begin{abstract}
The African Sahel provides the most dramatic example of multi-decadal climate variability that has been quantitatively and directly measured. Annual rainfall across this region fell by between 20 and 30 per cent between the decades leading up to political independence for the Sahelian nations (1930s-1950s) and the decades since (1970s-1990s). Climatic perspectives on the nature and causes of this period of desiccation have changed and, in some cases, matured as the years - and the drought - continued. This paper reviews these changing perspectives and reflects on three central questions: How unique an occurrence has been this desiccation in the recent human history of the Sahel? Can we find an adequate explanation for this desiccation in the natural forces that shape the climate system, or do we have to implicate human interventions in the system? Is our understanding of climate variability sufficient to allow us to develop seasonal rainfall forecasting capabilities for the region? (C) 2000 Elsevier Science Ltd. All rights reserved.
\end{abstract}

Keywords: Sahel drought; Desiccation; Global warming; Desertification; Seasonal rainfall forecasting

\section{Introduction}

There is no such thing as 'normal' rainfall in the Sahel. What matters fundamentally is not whether the mean annual rainfall is 200,400 or $600 \mathrm{~mm}$, but the spectrum of rainfall variability in time and space. Whilst well known to indigenous African societies (Mortimore and Adams, 1999), it took most of the 20th century for this lesson to be learnt by formal western science, first by Europe's governing elite during the era of colonisation and then, more recently, by the emerging national leadership of the Sahelian states and the international finance institutions of the post-colonial era (e.g. World Bank, 1996). The first maps of rainfall in Africa (e.g. Fig. 1) showing mean isohyets winding their precise way across the continent reflected the early Eurocentric view of climate as an equilibrium condition. These maps shaped the perception of Sahelian rainfall until the 1970s and beyond. Typical of this view was the claim that,

... if we have the mean of ten years rainfall it takes very considerable divergence from this mean in subsequent years to make any appreciable difference in the mean for the resultant number of years. (Knox, 1911, p. 11)

\footnotetext{
*Corresponding author. Tel.: + 01603-593162; fax: + 01603507784.

E-mail address: m.hulme@uea.ac.uk (M. Hulme).
}

Such maps and opinions suggested some equilibrium state in Sahelian climate and hid the far more important aspects of Sahelian rainfall such as the nature of its interannual and interdecadal variability. It represented an altogether too sanguine view of dryland rainfall variability and yet, subconciously perhaps, this view infected attitudes to Sahelian climate for most of the decades of the 20th century. Rainfall, however, fluctuates eratically over this 5 million $\mathrm{km}^{2}$ dryland region, leaving some areas in some years well supplied, yet other regions and other years dry and parched (Agnew, 1989). What is 'normal' to the Sahel is not some annual rainfall total averaged over 10,50 or 100 years, but variability of the rainfall supply in space and from year-to-year and from decade-to-decade. It is to this variability in rainfall supply, and not to its mean state, that most environmental and social systems have traditionally adapted, for example through pastoralism, diversification of income, and mobility (Mortimore, 1989). Yet the increasingly dry episode that commenced in the Sahel in the late 1960s, and which culminated in severe droughts in 1973, 1984 and 1990, placed these adaptive systems, already under stress from deteriorating regional political and global economic conditions, under a greater burden than they could cope with (Warren, 1995).

The African Sahel therefore provides the most dramatic example worldwide of climate variability that has been directly and quantitatively measured. Averaged 


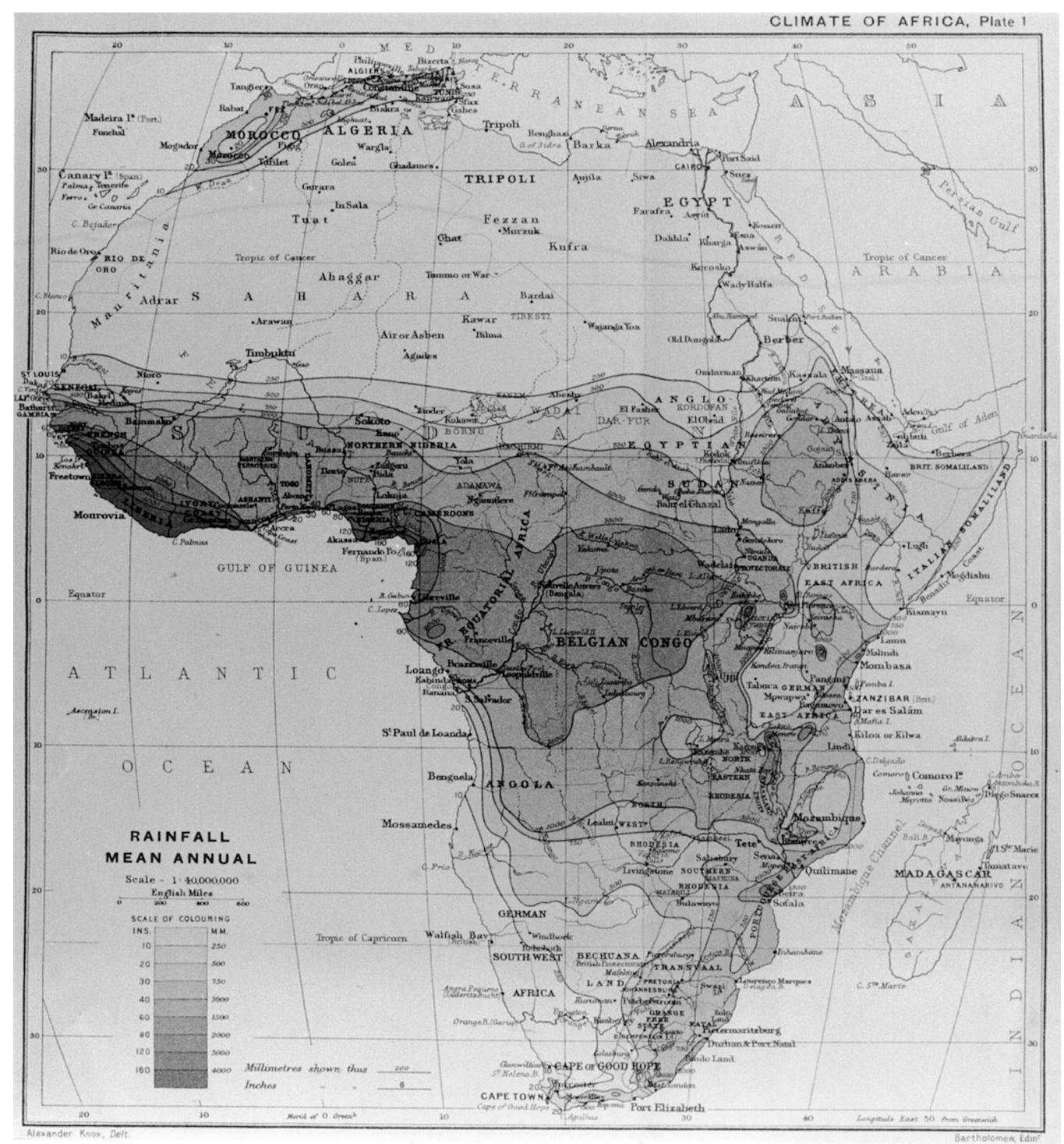

Fig. 1. Mean annual rainfall in Africa (mm) as depicted by Knox in 1911 (source: Knox, 1911).

over 30-year intervals, annual rainfall across this region fell by between 20 and 30 per cent between the decades (1930s-1950s) leading up to political independence for the Sahelian nations and the decades since (post-1960s). Climatic perspectives on the nature and causes of this period of multi-decadal desiccation have changed and, in some cases, matured as the years - and the drought - have continued. Section 3 of this paper reviews some of these perspectives and shows how the ideas behind Sahelian desiccation evolved along with both the climate and the changing paradigms within climate science. After more than 25 years of study, debate and opinion, three central questions in relation to Sahelian rainfall remain to be answered by climatologists:

- How unique an occurrence has been this desiccation in the recent human history of the Sahel?
- Can we find an adequate explanation for this desiccation in the natural forces that shape the climate system, or do we have to implicate human interventions in the system at either regional or global scales?

- Is our understanding of both natural and human causes of climate variability sufficient to allow us to develop with confidence seasonal rainfall forecasting capabilities?

Sections 4-6, address, respectively, these questions and summarise what we do and do not know about their answers. Finally, in Section 7, some conclusions are drawn about the implications for assessments of future rainfall supply in the region and how we might best prepare for that future. Before we embark on this review, however, Section 2 illustrates the basic problem of Sahel 

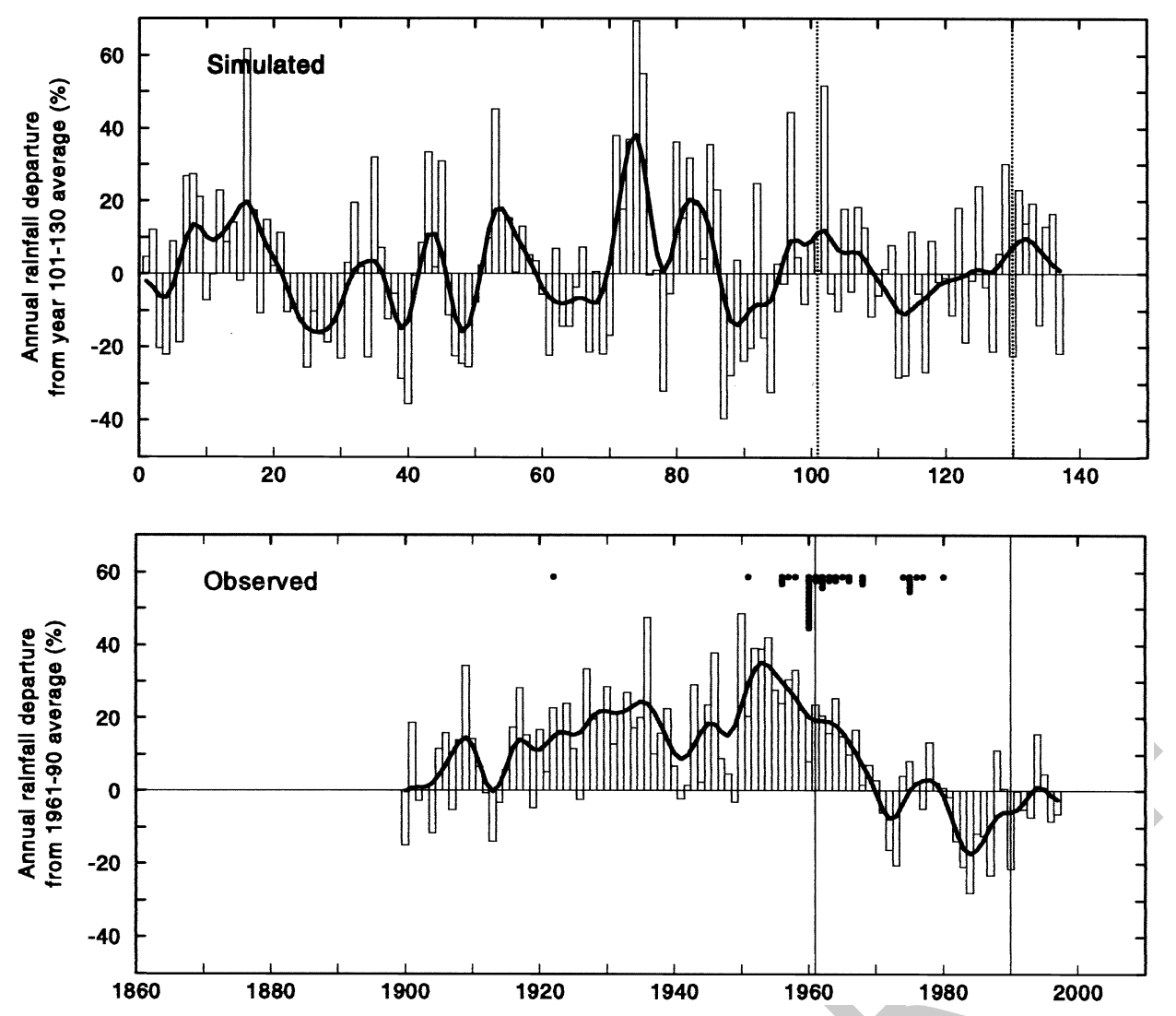

Fig. 2. Annual rainfall anomalies for the Sahel region expressed as per cent anomalies from the 1961-1990 average (which for observed is $428 \mathrm{~mm}$ ). Top panel: HadCM2 unforced model simulation for 140 model years. Bottom panel: observed record from 1900-1997. Dots here represent the date of independence for each African nation. The smooth curves in both plots are the result of 10-year low-pass filters.

rainfall: the multi-decadal nature of its variability and our inability to explain it.

\section{Two views of 20th century rainfall in the Sahel}

Fig. 2 (top panel) shows a 140-year sequence of annual rainfall variability in the Sahel region as simulated by a global climate model. This result is extracted from the HadCM2 coupled ocean-atmosphere global climate model of the UK Hadley Centre (Johns et al., 1997), one of the leading global climate models in the world. The simulation allows oceans and atmosphere to interact freely on all timescales, but does not include the effects of changing greenhouse gas and sulphate aerosol concentrations over this period and, as with most other coupled ocean-atmosphere models currently used in climate change experiments, does not allow land cover characteristics to change.

The magnitude of the year-to-year rainfall variability is quite well reproduced by the model, which also simulates short sequences of years above or below the mean (e.g. nine successive dry years in the ' 1880 s'and seven successive wet years in the '1940s'). But the model does not simulate any multi-decadal drying trends as seen in the Sahel since the late 1950s. This observed series is shown in the bottom panel in Fig. 2, these data being extracted from the dataset of Hulme (1994; updated). The drying trend commenced in the 1950s and continued through the period when most African nations received their independence (shown as dots in Fig. 2, bottom). Since the early 1970s, annual rainfall totals for the Sahel have fluctuated around the lower value of about $400 \mathrm{~mm}$ (cf. 520 mm during the period 1931-1960).

The difference in characteristics between the modelsimulated and observed Sahelian rainfall can be further explored using a simple autocorrelation function (acf). These are shown in Fig. 3 for the model simulation and for two different periods in the observed record: 1900-1950 and 1951-1997. The acfs for the model rainfall and for the observed 1900-1950 rainfall are both flat and show little structure, emphasising a lack of multi-year or decadal persistence in Sahelian rainfall. The observed period 1951-1997 is quite different, however, from the other two, with a very strong degree of persistence in Sahelian rainfall. Whatever mechanism has caused this post-1950s desiccation in the Sahel is missing in the HadCM2 model simulation. We return to discuss causal 


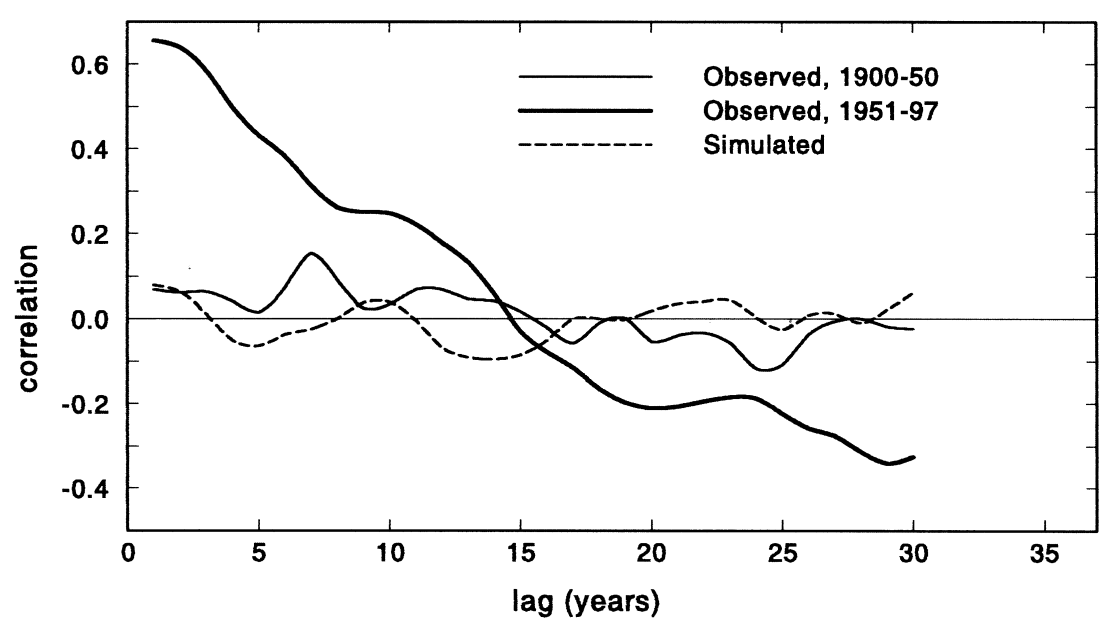

Fig. 3. Autocorrelation functions (smoothed) for the rainfall series shown in Fig. 2. The observed record has been divided into two periods: 1900-1950 and 1951-1997.

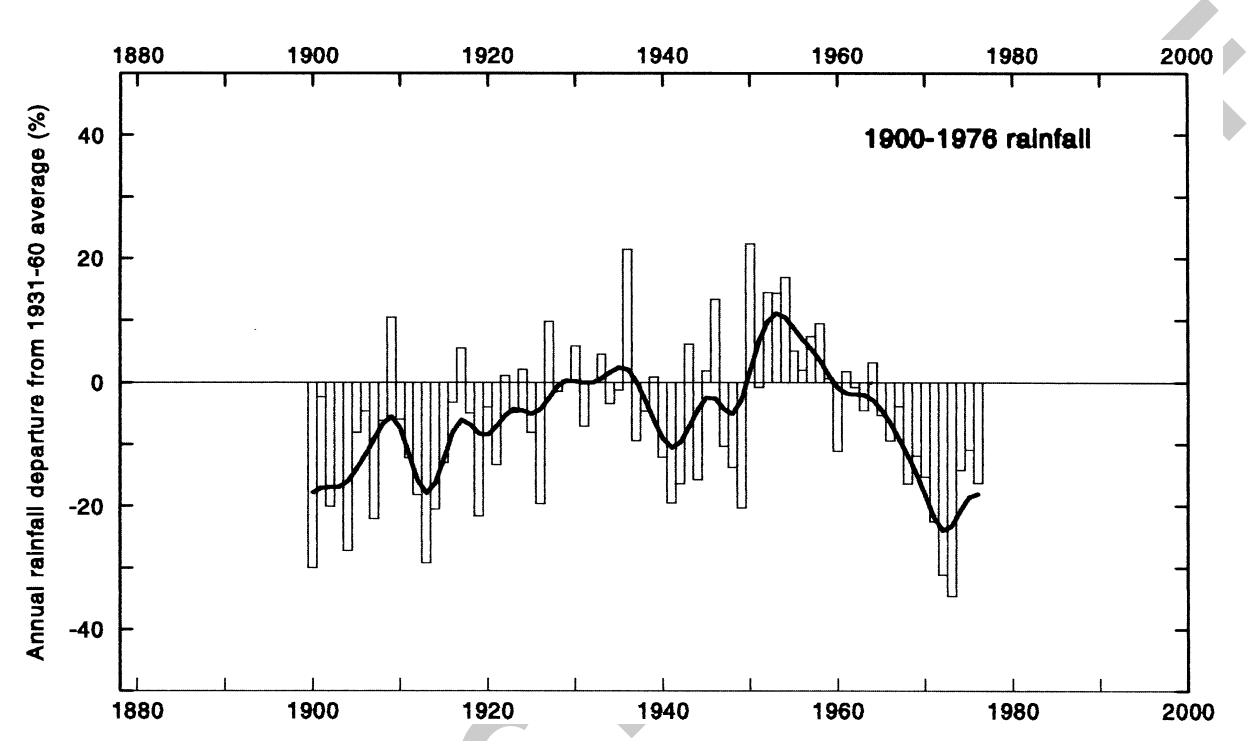

Fig. 4. Observed annual rainfall in the Sahel as perceived from 1977. Period is 1900-1976 and anomalies are with respect to the 1931-1960 mean. Smooth curve is the result of a 10 -year low-pass filter.

mechanisms in Section 4, but the next section characterises the changing perception and explanations of the Sahel drought between the 1970s and 1980s.

\section{Changing views of the Sahel drought}

One of the earliest responses to the Sahel droughts of the early 1970s (1972 and 1973 were the driest years recorded at the time in the Sahel; Fig. 4) was the formulation on both empirical (Otterman, 1974) and theoretical (Charney, 1975) grounds of the hypothesis that drought in such regions is self-reinforcing through changes in land cover and surface albedo. Thus, as a result of an early climate modelling experiment, the French meteorologist Jules Charney stated that:
... surface albedo's can have a substantial effect on climate in the Sahara and ... the biogeophysical feedback mechanism is a plausible one for causing such changes. (Charney et al., 1975, p. 435)

This basic feedback mechanism, although subsequently refined in a number of ways, remains a valid explanation for Sahelian desiccation, but its testing and verification has suffered from a paucity of long, homogenous observations of changing land cover characteristics across the Sahel (Nicholson et al., 1998). At the time, its implication that the Sahelian drought might continue in perpituity was contested on statistical grounds. For example, on the basis of a rather flimsy analysis of rainfall data from a handful of Sahelian stations, Alan Bunting and colleagues at the University of Reading concluded, 


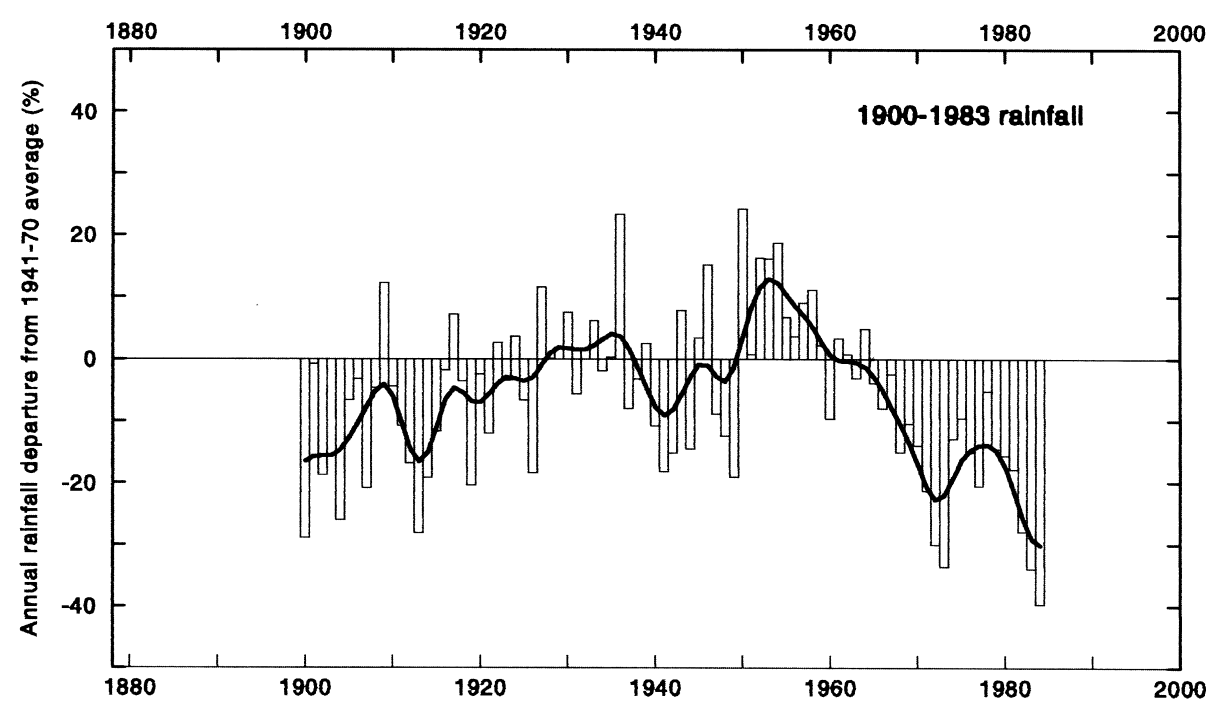

Fig. 5. Observed annual rainfall in the Sahel as perceived from 1985. Period is 1900-1984 and anomalies are with respect to the 1941-1970 mean. Smooth curve is the result of a 10 -year low-pass filter.

We have found no evidence leading us to expect that there will now be a long period of rainfall systematically below the average. (Bunting et al., 1976, p. 59)

The perspective that Bunting et al. were working from is shown in Fig. 4 and of course with hindsight the error in their conclusion is obvious. This debate in the mid1970s about how permanent this shift to drier conditions in the Sahel might be was vigorous. The late Hubert Lamb writing in 1977, but from a synoptic circulation perspective rather than from Charney's process-based approach, also suggested that the drought might continue for some time to come,

... the phenomenon giving rise to the droughts has a long history and ..... is not likely to disappear finally in the near future as part of any shorter-term cyclic phenomenon. (Lamb, 1977, p. 33)

Apart from Charney's pioneering work, there was virtually no climate modelling basis to any of these views and the weakness of purely statistical approaches is further illustrated by the study of river runoff records from the Sahel published in 1981 by two French hydrologists, Faure and Gac. By 1981, the drought had in its effect and continued for over a decade (Fig. 5; note the shift to the new 1941-1970 World Meteorological Organisation (WMO) normal period as the baseline) and the temptation to look for, and find, cycles in the data series was great. Faure and Gac confidently stated

... the present drought should end in 1985 with full wet conditions being re-established in about 1992 . If the same pattern continues, it is feared that a severe drought will occur around 2005. (Faure and Gac, 1981, p. 475)
But the drought did not end in 1985 and the three years 1983-1985 were the driest consecutive three years of the century, drier than even 1971-1973. With the benefit of these continued observations of low rainfall, Derek Winstanley restated his earlier conviction that the drought was part of a long-term trend and said,

there is no evidence of a bottoming out of the downward trend in rainfall in the sub-Saharan zone [and] a continuation of the trends must be considered as a distinct possibility, indeed, probability. (Winstanley, 1985, p. 81)

Still, a convincing mechanism for the desiccation was lacking and more systematic modelling studies of the phenomenon only really commenced later in the 1980 s (e.g. Sud and Fennessey, 1982; Palmer, 1986; Druyan and Hastenrath, 1991). Another very dry year in 1990 (Fig. 6; note another shift to the 1951-1980 WMO normal period), combined with the emerging consciousness of anthropogenic global warming due to elevated greenhouse gas concentrations (IPCC, 1990), led to a new spin being placed on the Sahel desiccation,

The trends are ominous - the suspicion that the Sahel drought has a similar cause (in the greenhouse effect) gains ground. (Pearce, 1991, p. 31)

a suspicion supported rather speculatively a couple of years later by Hulme and Kelly (1993).

This highly selective survey of some of the ideas and statements published during the 1970s and 1980s concerning Sahel drought, illustrates — with hindsight - how provisional and diverse were the views expressed and how the relentless development of the desiccation, as evidenced through the rainfall observations, influenced 


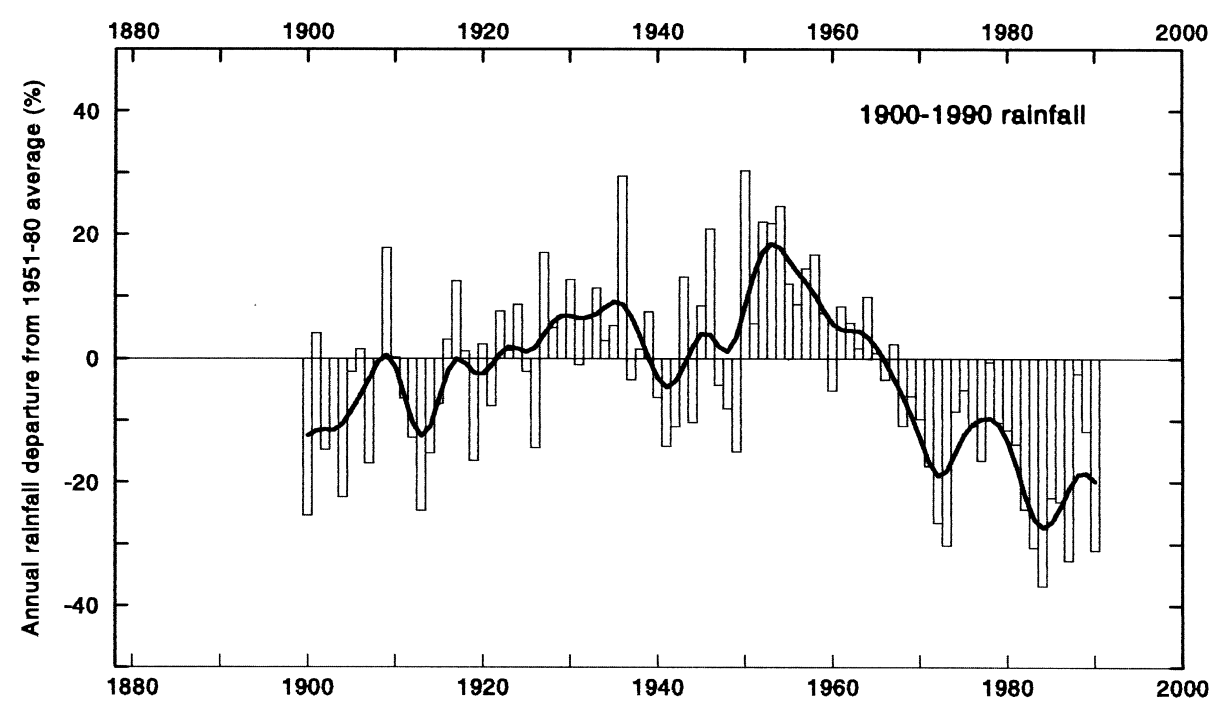

Fig. 6. Observed annual rainfall in the Sahel as perceived from 1991. Period is 1900-1990 and anomalies are with respect to the 1951-1980 mean. Smooth curve is the result of a 10-year low-pass filter.

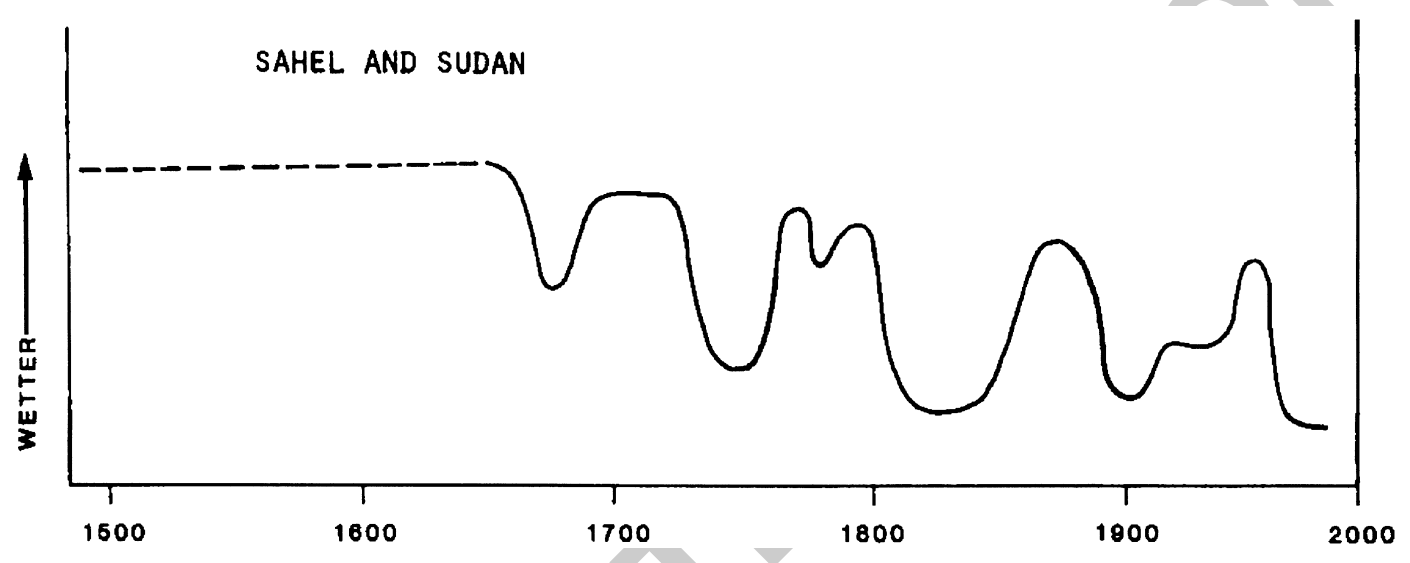

Fig. 7. Probable long-term rainfall trends in the Sahel and Soudan (no quantitative interpretation should be given to this curve) (source: Nicholson, 1982).

and shaped these views. Over this period of time (1973-1998), the standard WMO 30-year baseline period changed several times from 1931-1960 (still being used in some agrometeorological circles in the 1980s and even 1990s) to the current 1961-1990 period. The graphs in Figs. 4-6 reflect these changing baseline periods, while Fig. 2 uses the current 1961-1990 WMO baseline. The mean Sahel rainfall of these 30-year periods fell from $520 \mathrm{~mm}$ for $1931-1960$ to $512 \mathrm{~mm}$ (1941-1970), $488 \mathrm{~mm}$ (1951-1980) and then to $428 \mathrm{~mm}$ in 1961-1990. With data nearly complete for the 1971-2000 baseline, the mean for this latest period is likely to be about $410 \mathrm{~mm}$. The perspective offered by adopting the 1961-1990 baseline period (Fig. 2, bottom panel) suggests that it is maybe the wet decades of the 1920s, 1930s, and 1950s, that need a specific explanation rather than the dry decades of the post-1960s.

\section{How unique an event is the Sahel drought?}

While it is clear from the observational record of the 20th century that the magnitude and duration of the desiccation in the Sahel has been unprecedented (both in the Sahel and for any other dryland region; Middleton and Thomas, 1997), it is decidedly unclear whether or not this event is unique in the longer record of the Holocene. Are we therefore trying to explain a phenomenon that is unique as far as human history is concerned, or have there been other periods of such desiccation in the Sahel over recent millennia? In some ways we have not progressed very much further than the qualitative estimates of Sharon Nicholson and her caricature of Sahel rainfall over the last 500 years (Fig. 7). Proxy evidence (e.g. Jolly et al., 1998; Edmunds et al., 1999) has been neither widespread enough nor sufficiently quantitative 
to resolve and date Sahel droughts over recent millennia and certainly not accurate enough to state with confidence how frequent such episodes may have been (Tarhule and Woo, 1997; Brooks and Hulme, 2000).

A fundamental problem with reconstructing Sahel rainfall through proxy data is whether such multi-decadal episodes actually leave a sufficiently clear imprint on the local physical environment to allow such reconstruction. Put differently, what physical indicators of the late 20th century desiccation might be found and used by researchers in the year 2500 who were trying to quantify the duration and magnitude of this current dry episode? It may even be that the Blue Nile flood of 1988 (Sutcliffe et al., 1989) would leave more long-lasting fluvial evidence for future researchers than would the sequence of dry years, thus marking the late 20th century as a 'wet' era. Our failure to be able to quantify the severity and duration of Holocene droughts and the inability of global climate models to reproduce such multi-decadal desiccating trends, seriously hampers our efforts to understand the cause of this late 20th century phenomenon.

\section{What mechanisms do we understand are involved?}

Our understanding has nevertheless progressed and current research into the causes of the Sahelian desiccation tends to fall into one of two over-arching paradigms: remote forcing of Sahelian rainfall through ocean-atmosphere interaction and regional feedback processes involving land cover characteristics (in effect, developments of the Charney hypothesis). Each of these two general paradigms has a number of variants. For example, the idea that global greenhouse gas and sulphate aerosol forcing may influence the global oceanSahel rainfall relationship is being explored within the former paradigm, while the previously largely neglected role of Saharan-Sahelian dust aerosol forcing is being investigated within the latter (Tegen and Fung, 1995).

These two candidate explanations for the drying are by no means mutually exclusive, but the argument still continues as to which is dominant (Sud and Lau, 1996; Rowell, 1996; Xue and Shukla, 1998). Extensive work has been conducted into identifying the types of regional and global sea surface temperature (SST) anomaly patterns which are teleconnected with dry and wet Sahel years or periods (e.g. Ward, 1998). One of the critical distinctions to make in these remote relationships is between highfrequency (i.e., inter-annual) and low-frequency (i.e., multi-decadal) rainfall variability. The dominant SST anomaly configuration associated with the Sahelian desiccation has been an inter-hemispheric temperature contrast (Fig. 8). The pattern whereby southern oceans are warmer and northern oceans are cooler than average has tended to persist during multi-year periods of Sahelian desiccation. This low frequency relationship can account for a large part of the longer-term trend in Sahel rainfall without being able to account for the (sometimes substantial) year-to-year variations around this trend.

It is not clear what underlies these multi-decadal modes of variability in the world's oceans (Street-Perrott, 1990; Ward, 1998) and as was suggested in Section 2, present-day ocean-atmosphere climate models are not capable of generating multi-decadal desiccation episodes

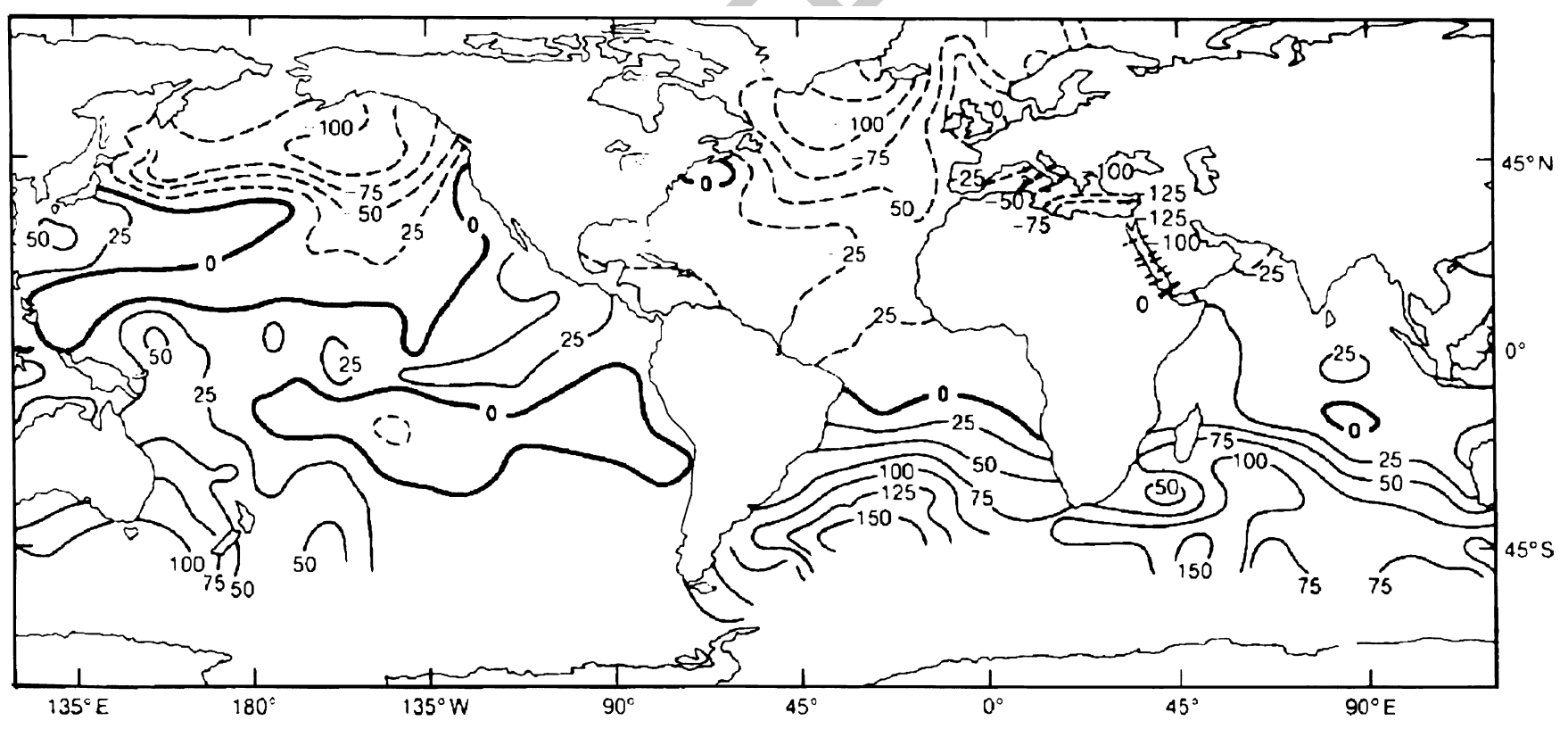

Fig. 8. Pattern of sea-surface temperature anomalies associated with low-frequency Sahel rainfall variability (unrotated EOF3 from 1901 to 1980 data, extracted from Folland et al., 1991). 
in the Sahel when left unforced. Nevertheless, experiments performed with an atmosphere-only climate model forced with observed SSTs from 1900 onwards have supported claims that this SST-rainfall link is dominant (Rowell et al., 1995). The high-frequency variability component of Sahel rainfall tends to be more related to SST anomaly patterns in the tropical Atlantic (Chang et al., 1997) or associated with the El Niño/Southern Oscillation (Nicholson and Kim, 1997). Relationships on both time-scales are of potential importance for the development of seasonal rainfall forecasting in the Sahel (see below).

But there is another line of thought which does not necessarily involve global ocean teleconnections. The unparalleled persistence of the Sahel dessication has tempted many into invoking self-reinforcing regional feedback processes involving land-surface-atmosphere interactions. Josef Otterman and Jules Charney were the early proponents of this idea and during the 1980s and 1990s a steady stream of climate modelling studies have demonstrated the capacity for major land cover
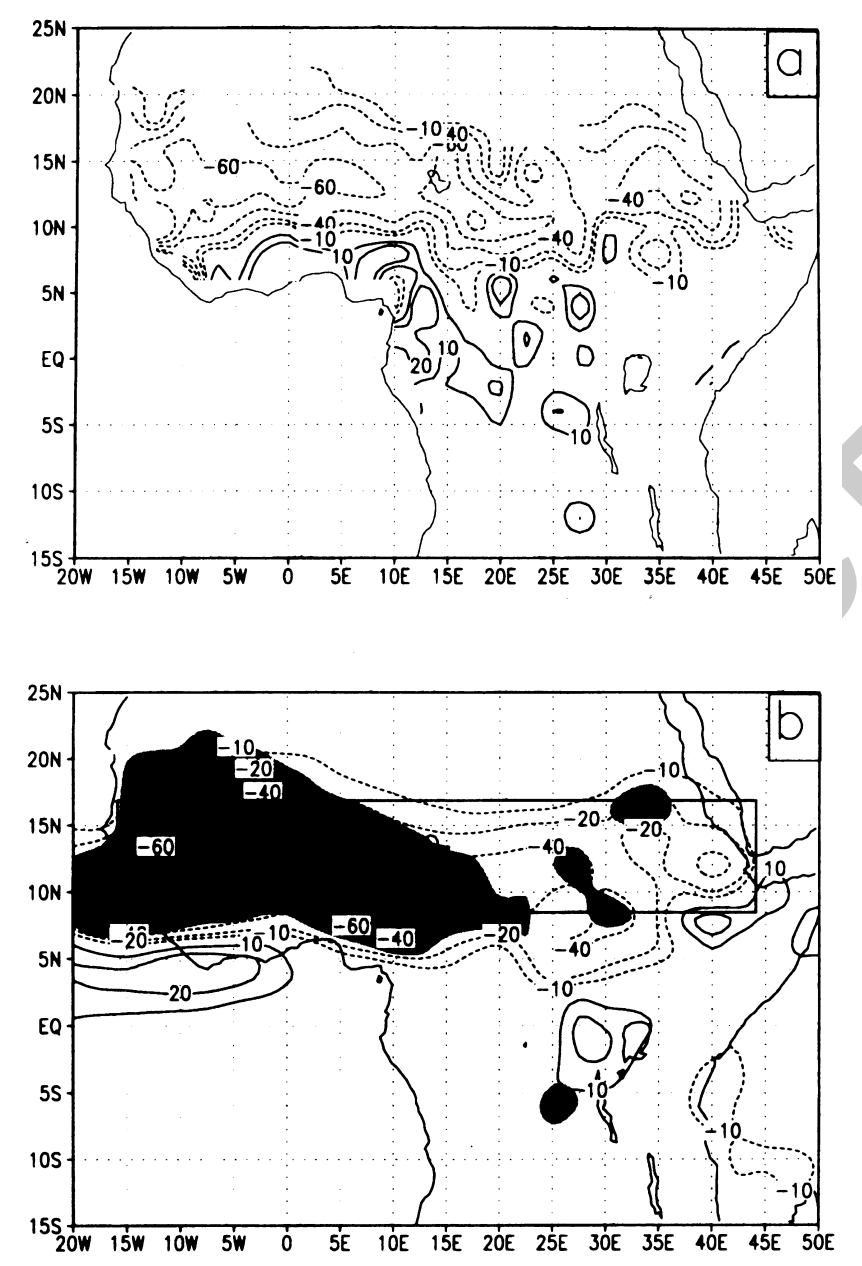

Fig. 9. Observed (top) and model-simulated (bottom) precipitation anomalies for the 1980s minus the 1950s (source: Xue, 1997). modification across the Sahel to provoke multi-year droughts not dissimilar to those observed (Sud and Fennessey, 1982; Cunnington and Rowntree, 1986; see Nicholson, 1988, for a review). The most recent proponent of the idea has been Yongkang Xue from the University of Maryland and in a series of recent papers has again made the case for a variant of the Charney hypothesis to account for much of the Sahelian desiccation (Fig. 9; Xue, 1997). One of the enduring weaknesses of these modelling studies has been the imposition in the model of land cover changes across the Sahel on a scale and severity that is unjustified given the surface and satellite measurements of land cover characteristics that we have. It is one thing to say that Sahel rainfall would be reduced by 25 per cent over three decades were acacia savanna vegetation across the entire Sahel replaced with open grassland savanna, but quite another to insist that such sweeping land cover modification has actually occurred. Our limited land cover observations over the last four decades do not support such an assertion (Nicholson et al., 1998).

There remain therefore at least two climate modelling experiments still to be undertaken before we can fully reconcile some of these apparently competing ideas. One would be to repeat Xue's experiments, but imposing his land cover modification on, say, 25 per cent of the Sahel region, the localities of the perturbation being randomly chosen to reflect the heterogenous nature of land cover modification across the Sahel. This would be closer to a simulation experiment of land cover forcing than the sensitivity experiments thus far conducted. The second experiment would be to conduct a fully coupled ocean-atmosphere-biosphere climate model simulation of 20th century of Sahel rainfall. Some coupled ocean-atmosphere climate models have recently been used to conduct experiments with a fully interactive biosphere (Peter Cox, Hadley Centre, personal communication), thus in principle allowing the Charney mechanism to be adequately represented in the model climate. Results from such experiments have not yet been widely analysed or published.

\section{The potential for seasonal rainfall forecasting}

The failure to identify a convincing, and ultimate, meteorological explanation for the desiccation of the Sahel has not inhibited the exploration of the extent to which seasonal rainfall in the Sahel can be forecast. The example cited earlier of Faure and Gac (1981) is one way not to make the attempt, but there have been more successful and physically based efforts. The longest running and most widely distributed forecast probably originates from the UK Met. Office and uses the wellestablished teleconnections between Sahel rainfall and various oceanic SST anomaly patterns to issue a forecast 


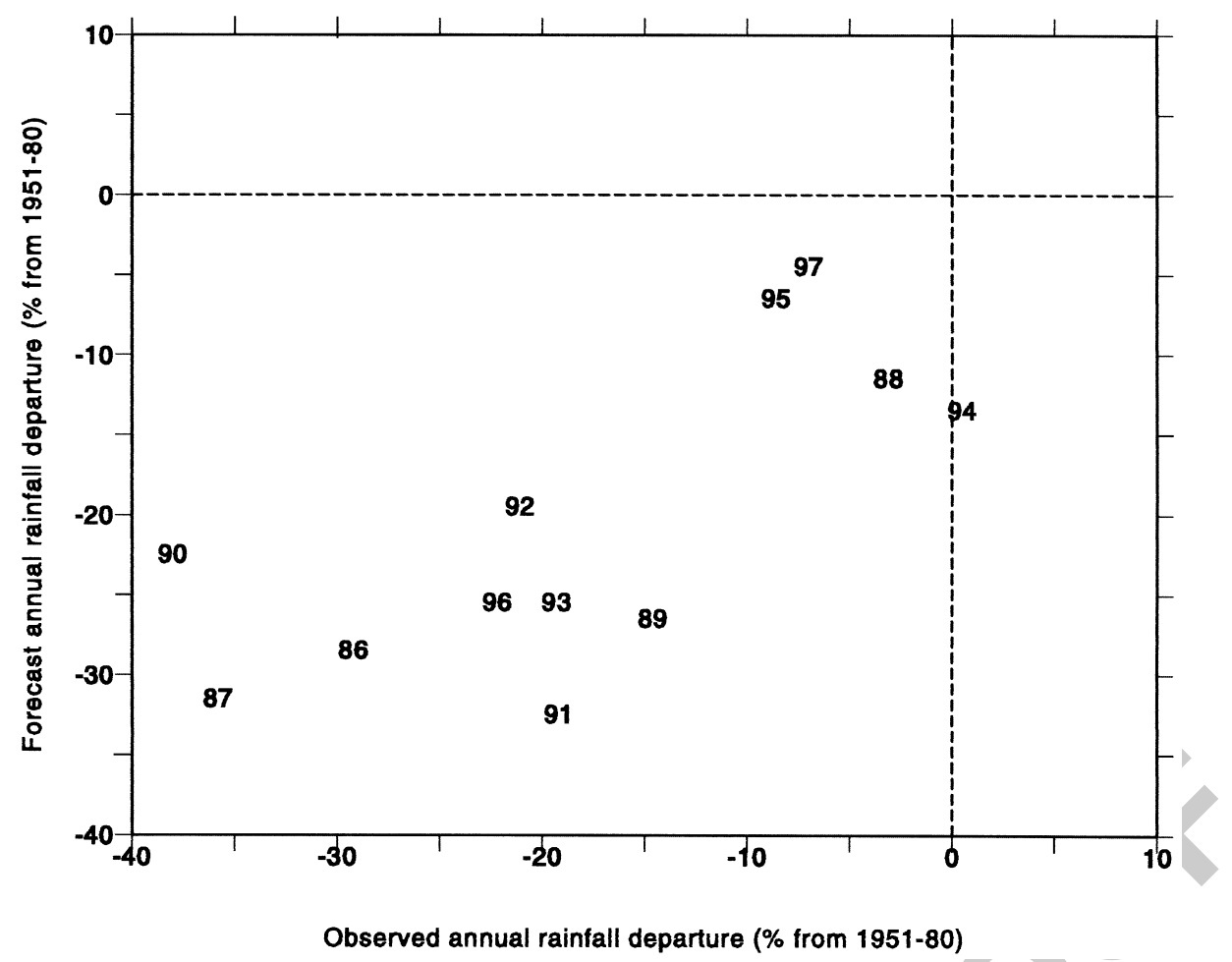

Fig. 10. Observed vs. forecast annual rainfall anomalies (per cent from 1951-1980 mean) for the Sahel for $1986-1997$ (years shown as '92' = 1992). Forecast rainfall is from the UK Met. Office July forecasts for each year.

for the Sahel in the May and July of each year (Folland et al., 1991). This has been published for each season since and, averaged over the Sahel region as a whole, has achieved a degree of success (Fig. 10). The less dry years of 1995 and 1997 were well forecast, as were the dry years of 1986 and 1987. The techniques employed make use of both the low- and high-frequency components of SST forcing discussed above and have been tested in hindcast mode using an atmospheric global climate model. The forecasts achieve the level of success they do without any consideration of regional land surface-atmosphere interactions.

Translating such region-wide, seasonal forecasts into information that is useful at the local or national scales remains a much bigger challenge (Hulme et al., 1992; Washington and Downing, 1999) and will only be accomplished through the careful involvement of regional stakeholders. This is work that needs further development (e.g. NOAA, 1999) if the forecast potential is to achieve tangible benefits for the region.

\section{Conclusions}

The prolonged and severe desiccation of the Sahel over three decades or more is the largest manifestation of multi-decadal rainfall variability observed anywhere in the world this century. Temptations to attribute such a change in regional climate to the degradation of the regional land cover - either through advertent or inadvertent land use change - or to the general warming of the planet are great. Such attribution, if warranted, would have major implications for the interpretation of Sahelian desiccation and its political repercussions (Hulme and Kelly, 1993). The former would imply that land cover transformation, partly driven by socio-economic processes in the region, was to blame and that the desiccation might, in principle, be reversible by the pursuit of different land use policies. The latter attribution would point the finger towards the increasingly carbonised global energy economy which is driving global warming, but for which the Sahelian nation states can hardly take responsibility.

Neither of these two attributions, however, is warranted at present. It is quite conceivable that the root cause of the Sahelian desiccation is natural in origin and may lie in the low-frequency and a periodic response of the coupled ocean-atmosphere system to random forcing, perhaps exaggerated in part by the potential for large-scale land cover-atmosphere feedback processes in this vast dryland region. More than 25 years after the initial sequence of dry years that triggered such a wide range of social, environmental and political responses in the Sahel and beyond, it is perhaps depressing that we can only make such an inconclusive attempt at an explanation. Yet progress has been made in our 
understanding and the embryonic seasonal rainfall forecasting capability now in place is evidence of this progress.

We would be much better placed to evaluate conclusively the above candidate explanations were we to have established the extent to which this recent desiccating trend has recurred in the recent or more distant past, i.e., before the period of instrumental measurement. Again we need to be ambivalent on this point, although it is interesting to note that no long, coupled ocean-atmosphere global climate model simulation has been able to reproduce a desiccating trend in the Sahel of the magnitude and duration of that observed. It is also important to note that with the persistence of dry (i.e., post-1960s) conditions in the Sahel through the 1980s and 1990s that a re-casting of the problem may be necessary. It is perhaps the wet decades of the 1920s, 1930s and 1950s for which we should be seeking a fundamental explanation rather than the drier years of the post-independence era. What was it about the state of the ocean-atmosphere-biosphere during those decades that was more favourable to the delivery of higher levels of rainfall into the Sahel? Although in one sense this does not make the question any easier to solve - physically there was less rainfall post-1960s than pre-1960s and this fact has to be explained in some way - such a perspective may alter the way we try and explain the multi-decadal variability of Sahel climate. It may also alter the way we interpret its implications for future society and environment in the region.

Finally, the experience of the Sahel over the last three decades presents a challenge to those who seek to look further ahead and attempt to evaluate and quantify the impact on human and ecosystem welfare of future global warming. The desiccation recently observed in the Sahel (a 20-30 per cent decline in rainfall) is greater than nearly all the predictions of global warming-induced rainfall change for this region made by global climate models (Hulme et al., 2000). This suggests that either natural variability or the impact of land cover changes on regional climate may be as important, or more important, for future rainfall levels in the Sahel than global warming per se. Whilst this conclusion is intriguing from a climate modelling perspective, the implications present a much greater challenge for environmental, social and economic analysts. If we cannot quantify empirically the impact on Sahelian welfare of a $\sim 25$ per cent decline in rainfall - and no-one has satisfactorily done so because of the difficulty of disentangling the roles played by climate and non-climatic factors in making people vulnerable and because the endogenous adaptation capacity to climate variability of people in the Sahel is higher than we imagine (e.g. Raynaut; Mortimore and Adams, this volume) - can we sensibly think that we can quantify theoretically the impact of a future, indeterminate change in global climate on human and planetary welfare?

\section{Acknowledgements}

This paper is based on a talk given at a one-day meeting of the Royal Geographical Society in May 1998, marking the 25th anniversary of the Sahel drought of 1973. The rainfall graphs are therefore only presented to the end of 1997, even though later data are now available. The suggestions of an anonymous reviewer are acknowledged.

\section{References}

Agnew, C.T., 1989. Spatial aspects of drought in the Sahel. Journal of Arid Environments 18, 279-293.

Brooks, N., Hulme, M., 2000. 1000 years of rainfall variability in the Sahel: an evaluation of a long climate model simulation against observational data. The Holocene, (submitted for publication).

Bunting, A.H., Dennett, M.D., Elston, J., Milford, J.R., 1976. Rainfall trends in the West African Sahel. Quarterly Journal of the Royal Meteorological Society 102, 59-64.

Chang, P., Ji, L., Li, H., 1997. A decadal climate variation in the tropical Atlantic Ocean from thermodynamic air-sea interactions. Nature $385,516-518$.

Charney, J.G., 1975. Dynamics of deserts and drought in the Sahel. Quarterly Journal of the Royal Meteorological Society 101, 193-202.

Charney, J.G., Stone, P.H., Quirk, W.J., 1975. Drought in the Sahara: a biogeophysical feedback mechanism. Science 187, 434-435.

Cunnington, W.M., Rowntree, P.R., 1986. Simulations of the Saharan atmosphere: dependence on moisture and albedo. Quarterly Journal of the Royal Meteorological Society 112, 971-999.

Druyan, L.M., Hastenrath, 1991. Modelling the differential impact of 1984 and 1950 sea-surface temperatures on Sahel rainfall. International Journal of Climatology 11, 367-380.

Edmunds, W.M., Fellman, E., Goni, I.B., 1999. Lakes, groundwater and palaeohydrology in the Sahel of NE Nigeria: evidence from hydrogeochemistry. Journal of Geological Society 156, 345-356.

Faure, H., Gac, J., 1981. Will the Sahelian drought end in 1985 ? Nature 291, 475-478.

Folland, C.K., Owen, J.A., Ward, M.N., Colman, A.W., 1991. Prediction of seasonal rainfall in the Sahel region using empirical and dynamical methods. Journal of Forecasting 10, 21-56.

Hulme, M., 1994. Validation of large-scale precipitation fields in General Circulation Models. In: Desbois, M., Désalmand, F. (Eds.), Global Precipitations and Climate Change. Springer, Berlin, pp. 387-405.

Hulme, M., Kelly, P.M., 1993. Exploring the linkages between climate change and desertification. Environment 35, 4-11 and 39-45.

Hulme, M., Biot, Y., Borton, J., Buchanan-Smith, M., Davies, S., Folland, C.K., Nicholds, N., Seddon, D., Ward, M.N., 1992. Seasonal rainfall forecasting for Africa. Part II: application and impact assessment. International Journal of Environmental Studies (A) 40, $103-121$.

Hulme, M., Doherty, R.M., Ngara, T., New, M.G., Lister, D., 2000. African climate change: 1900-2100 Climate Research (in press).

IPCC 1990. Climate change: the IPCC scientific assessment In: Houghton, J.T., Jenkins, G.J., Ephraums, J.J., (Eds.), Cambridge University Press, Cambridge, 364pp.

Johns, T.C., Carnell, R.E., Crossley, J.F., Gregory, J.M., Mitchell, J.F.B., Senior, C.A., Tett, S.F.B., Wood, R.A., 1997. The second Hadley Centre coupled ocean-atmosphere GCM: model description, spinup and validation. Climate Dynamics 13, 103-134. 
Jolly, D., Harrison, S.P., Damnati, B., Bonnefille, R., 1998. Simulated climate and biomes of Africa during the Late Quaternary: comparison with pollen and lake status data. Quaternary Science Reviews 17, 629-657.

Knox, A., 1911. The Climate of the Continent of Africa. Cambridge University Press, Cambridge, UK, 552pp.

Lamb, H.H., 1977. Some comments on the drought in recent years in the Sahel-Ethiopian zone of North Africa p. 33-37. In: Dalby, D., Harrison-Church, R.J., Bazzaz, F., (Eds.), Drought in Africa 2. London, 200pp.

Middleton, N.J., Thomas, D.S.G., (Eds.) 1997. World Atlas of Desertification, 2nd Edition. Arnold, London, 182pp.

Mortimore, M., 1989. Adapting to Drought: Farmers, Famines, and Desertification in Western Africa. Cambridge University Press, Cambridge.

Mortimore, M.J., Adams, W.M., 1999. Working the Sahel. Routledge, London, UK, 224pp.

Nicholson, S.E., 1982. The Sahel: A Climatic Perspective. Club du Sahel, Paris, France.

Nicholson, S.E., 1988. Land surface-atmosphere interaction: physical processes and surface changes and their impact. Progress in Physical Geography 12, 36-65.

Nicholson, S.E., Kim, J., 1997. The relationship of the El Niño-Southern Oscillation to African rainfall. International Journal of Climatology 17, 117-136.

Nicholson, S.E., Tucker, C.J., Ba, M.B., 1998. Desertification, drought and surface vegetation: an example from the West African Sahel. Bulletin of American Meteorological Society 79, 815-830.

NOAA 1999. An experiment in the application of climate forecasts: NOAA-OGP activities related to the 1997-98 El Niño event. OGP/NOAA/US Department of Commerce, Washington, DC, USA, 134pp.

Otterman, J., 1974. Baring high-albedo soils by overgrazing: a hypothesised desertification mechanism. Science 186, 531-533.

Palmer, T.N., 1986. Influence of the Atlantic, Pacific and Indian Oceans on Sahel rainfall. Nature 322, 251-253.

Pearce, D., 1991. A sea change in the Sahel. New Scientist. 30-31.

Rowell, D.P., 1996. Response to comments by Sud and Lau: further analysis of simulated interdecadal and interannual variability of summer rainfall over tropical north Africa. Quarterly Journal of the Royal Meteorological Society 122, 1007-1013.
Rowell, D.P., Folland, C.K., Maskell, K., Ward, M.N., 1995. Variability of summer rainfall over tropical north Africa 1906-92: observations and modelling. Quarterly Journal of the Royal Meteorological Society $121,669-704$.

Street-Perrott, F.A., Perrott, R.A., 1990. Abrupt climate fluctuations in the tropics: the influence of Atlantic Ocean circulation. Nature 343, 607-612.

Sud, Y.C., Fenessey, M.J., 1982. A study of the influence of surface albedo on July circulation in semi-arid regions using the GLAS GCM. Journal of Climatology 2, 105-125.

Sud, Y.C., Lau, W.K-M., 1996. Comments on paper "Variability of summer rainfall over tropical North Africa (1906-1992): observations and modelling". Quarterly Journal of the Royal Meteorological Society 122, 1001-1006.

Sutcliffe, J.V., Dugdale, G., Milford, J.R., 1989. The Sudan floods of 1988. Hydrological Sciences Journal 34, 355-364.

Tarhule, A., Woo, M-K., 1997. Towards an interpretation of historical droughts in northern Nigeria. Climatic Change 37, 601-616.

Tegen, I., Fung, I., 1995. Contribution to the atmospheric mineral aerosol load from surface land modification. Journal of Geophysical Research 100, 18707-18726.

Ward, M.N., 1998. Diagnosis and short-lead time prediction of summer rainfall in tropical North Africa at interannual and multidecadal timescales. Journal of Climate 11, 3167-3191.

Warren, A., 1995. Changing understandings of African pastoralism and the nature of environmental paradigms. Transactions of the Institution of British Geographers 20, 193-203.

Washington, R., Downing, T.E., 1999. Seasonal forecasting of African rainfall: prediction, responses and household food security. Geographical Journal 165, 255-274.

World Bank 1996. Toward environmentally sustainable development in sub-Saharan Africa. World Bank, Washington, DC, USA, $140 \mathrm{pp}$.

Xue, Y., 1997. Biosphere feedback on regional climate in tropical North Africa. Quarterly Journal of the Royal Meteorological Society 123, 1483-1515.

Xue, Y., Shukla, J., 1998. Model simulation of the influence of global SST anomalies on Sahel rainfall. Monthly Weather Review 126, 2782-2792. 